\title{
Author Correction: Positive memory specificity is associated with reduced vulnerability to depression
}

Adrian Dahl Askelund (D), Susanne Schweizer (D), lan M. Goodyer and Anne-Laura van Harmelen (i)

Correction to: Nature Human Behaviour https://doi.org/10.1038/s41562-018-0504-3, published online 14 January 2019.

In the version of this article initially published, reference \#8 (originally Goodyer, I. M., Herbert, J., Tamplin, A. \& Altham, P. M. E. First-episode major depression in adolescents. Br. J. Psychiatry 176, 142-149 (2000).) should have been Goodyer, I. M., Herbert, J., Tamplin, A. \& Altham, P. M. E. Recent life events, cortisol, dehydroepiandrosterone and the onset of major depression in high-risk adolescents. Br. J. Psychiatry 177, 499-504 (2000). The error has been corrected in the HTML and PDF versions of the article. 